\title{
Doze Profetas ou Livro dos Doze?
}

\author{
Maria de Lourdes Corrêa Lima
}

\section{Introdução}

Na última década, impôs-se nos estudos bíblicos uma forte tendência a estudar os assim chamados "profetas menores" não somente cada qual em si mesmo, mas no seu conjunto. Estudos há que, baseados primeiramente em dados da tradição manuscrita, admitem a unidade redacional e teológica destes escritos e preocupam-se em desenvolver esta tese, de modo a demonstrá-la, explicá-la, ordenar cronologicamente os escritos, ou ainda procuram compreender o conjunto como um todo coerente e cada uma das partes dentro deste todo. A questão se realmente estes doze escritos possuem uma unidade é, neste contexto, fundamental, pois é capaz de orientar toda a pesquisa ulterior, com grandes conseqüências hermenêuticas. Pois se não se trata de doze livros, mas de um único livro, então, cada um dos pequenos escritos, seja de Oséias, Amós ou Jonas, por exemplo, deve ser entendido não mais em si mesmo, mas como parte de um conjunto que o ultrapassa. Se, ao contrário, não há uma unidade entre eles, então não teria sentido vê-los interrelacionados, mas a praxe de lê-los individualmente deveria ser mantida ${ }^{1}$. É sobre esta questão que se debruça o presente estudo, que persegue a finalida-

\footnotetext{
1 Aqui nos detemos no primeiro nível de leitura do texto, sem tocar o princípio hermenêutico enunciado pela Dei Verbum (n. 12), e que deve ser plenamente respeitado, acerca da leitura dos textos bíblicos considerando-se a unidade de toda a Escritura.
} 
de de apontar alguns elementos - mesmo se introdutórios e provisórios - que permitam alguma orientação neste campo.

Para tanto, apresenta-se de início uma breve história da questão, atendendo tão somente ao ponto de nosso interesse. Renuncia-se, com isto, a um detalhamento das teses dos diversos autores que fugisse à pergunta em pauta. Os dados aí levantados serão em seguida discutidos. Por fim, procurar-se-á delinear os pontos referenciais neste tema, a fim de traçar pistas para a pesquisa sobre os doze profetas.

\section{A questão}

\subsection{Localização}

A pergunta acerca da unidade dos doze profetas "menores" aparece esporadicamente nas três primeiras décadas neste século ${ }^{2}$. Partindo da observação de incongruências presentes nestes escritos, em artigo de 1921, K. Budde $^{3}$ as atribui a um trabalho consciente de redação que procurou criar, a partir dos diversos pequenos profetas, um único livro, a fim de apresentá-lo como escritura sagrada em contraposição a grupos que aceitariam somente a Torah. A redação final ter-se-ia dado antes da introdução na coleção do livro de Jonas e da tradução grega da Septuaginta, sendo datada em torno do século IV-III a.C. Em 1935, R.E. Wolfe ${ }^{4}$ afirma a tese de que os doze chegaram a formar um único livro em razão de um trabalho redacional múltiplo que, através da inserção de material, criou conexões entre os diversos escritos. A partir da distinção entre material autêntico e secundário e de sua comparação, estabelece diferentes fases de crescimento da coleção, que se daria da metade do século VII até 225 a.C., ou seja, antes da aceitação dos Doze como livro sagrado, quando então se excluiria qualquer outro acréscimo.

Por falta de comprovação de suas hipóteses, estes autores não chegaram a impor um novo rumo aos estudos, de modo que a exegese no século passado continuou basicamente considerando cada um dos profetas individualmente. Foi no final da década de setenta, em âmbito americano, que

\footnotetext{
2 No entanto, alguns autores anteriores haviam já entrevisto o problema. Assim, por exemplo, H. Ewald (cf. Die Propheten des Alten Bundes, I, Göttingen 1867, 73-81) vê nos títulos dos escritos indícios de uma redação que os teria reunido em pequenas coleções, além de, em pequena dimensão, acrescentar material de sua autoria.

3 Cf. K. Budde, "Eine folgenschwere Redaktion des Zwölfprophetenbuchs", ZAW 39 (1921) 218-229.

4 Cf. R.E. Wolfe, "The Day of Yahweh Editor in the Book of the Twelve", JBL 54 (1935) 90129. Este artigo aproveita os dados de sua tese doutoral intitulada The Editing of the Book of the Twelve. A Study of Secondary Material in the Minor Prophets, Harvard, 1933.
} 
surgiu o primeiro estudo depois de longos anos de silêncio. Em 1977, trabalhando sob a perspectiva canônica, R. Clements ${ }^{5}$ defendeu, em trabalho publicado, a unidade de mensagem dos Doze. Sob diferente perspectiva, de corte redacional, em 1979 vem à luz a tese doutoral de D. Schneider ${ }^{6}$, que procurou reconstruir a formação do conjunto em quatro fases redacionais. $\mathrm{O}$ tema alcançou outros âmbitos geográficos e foi aprofundado na década de oitenta, em teses doutorais e artigos especializados ${ }^{7}$, dentre os quais se destaca o de P. Weimar ${ }^{8}$, que, comparando a última redação do livro de Abdias com textos secundários dos outros profetas menores, conclui que a forma final daquele escrito profético encontra-se ligada à redação dos Doze. Em 1987, o estudo de E. Bosshard ampliou as perspectivas ao comparar a redação dos Doze com o livro de Isaías, chegando à conclusão de que ambos foram fruto de um mesmo grupo de redatores ${ }^{9}$.

Foi no entanto a partir da década de noventa que floresceu mais abundantemente a literatura em torno desta temática. São estudos que consideram um profeta no conjunto dos Doze, ou ainda estudos complexivos sobre o Livro dos Doze; surgem igualmente trabalhos sobre a profecia em geral enfocada a partir desta perspectiva.

Os primeiros profetas individuais a serem estudados em relação ao conjunto dos Doze foram Abdias, Malaquias e Jonas ${ }^{10}$. Em seguida, Naum,

5 Cf. R. Clements, "Patterns in the Prophetic Canon", in G.W. Coats - B.O. Long, Canon and Autority (Philadelphia 1977) 43-56.

6 D. Schneider, The Unity of the Book of the Twelve, Yale, 1979, não publicada. O material não é de fácil acesso e é conhecido através de referências de outros autores.

7 Assim, a tese doutoral de A.Y. Lee, The Canonical Unity of the Scroll of the Minor Prophets (Baylor University 1985, não publicada) e os estudos de N. Gottwald ("Tragedy and Comedy in the Latter Prophets", Semeia 32, 1984, 83-96) e H. Marks ("The Twelve Prophets", in R. Alter - F. Kermode, The Literary Guide to the Bible, Cambridge 1987, 207 232).

8 Cf. P. Weimar, “Obadja: Eine redaktionskritische Analyse”, BN 27 (1985) 94-99.

9 Cf. E. Bosshard, "Beobachtungen zum Zwölfprophetenbuch", BN 40 (1987) 30-62. Comparação com Isaías é trabalhada também no artigo de O.H. Steck, Der Abschluss der Prophetie im Alten Testament. Ein Versuch zur Frage der Vorgeschichte des Kanons, Neukirchen 1991. 10 Cf. P. Weimar, "Obadja: eine redaktionskritische Analyse”, BN 27 (1985) 94-99; E. Bosshard - R.G. Kratz, "Maleachi im Zwölfprophetenbuch", BN 52 (1990) 27-46; B.G. Curtis, "The Daughter Zion Oracles and the Appendices to Malachi: Evidence on the Latter Redactors and Redactions of the Book of the Twelve", in Society of Biblical Literature - Seminar Papers (SBLSP) 37/2 (Atlanta 1998) 872-892; E. Dick, "Jonah Among the Prophets. A Study in Canonical Context", JETS 33 (1990) 63-73; O.H. Steck, "Zur Abfolge Maleachi - Jona in 4Q76 (4QXIIa)", ZAW 108 (1996) 249-253; B. Ego, "The Repentance of Nineveh in the Story of Jonah and Nahum's Prophecy of the City's Destruction - Aggadic Solutions for an Exegetical Problem in the Book of the Twelve", in SBLSP 39 (Atlanta 2000) 243-253. 
Oséias, Ageu-Zacarias, Habacuc e Sofonias ${ }^{11}$. Mais recentemente, Miquéias, Amós e Joel ${ }^{12}$.

Nos estudos complexivos sobre os Doze procura-se determinar os indícios que provariam a unidade do Livro, desenvolver uma metodologia de trabalho apropriada, bem como descrever a história da formação do conjunto. O primeiro estudo significativo surge em 1990, da mão de P.R. House ${ }^{13}$. Em 1993, dois livros de J. Nogalski influenciarão grandemente os trabalhos posteriores nesta matéria ${ }^{14}$. Segue-se a publicação da tese doutoral de B.A. Jones $^{15}$. Com data de 1997, dois estudos apresentam-se como significativos:

11 Cf. J. Nogalski, "The Redactional Shaping of Nahum 1 for the Book of the Twelve", in P.R. Davies - D.J.A. Clines (ed.), Among the Prophets (JSOT SS 144; Sheffield 1993) 193202; D.L. Christensen, "The Book of Nahum: A History of Interpretation", in J.W. Watts P.R. House (ed.), Forming Prophetic Literature (Sheffield 1996), 187-194; J. Jeremias, "Die Anfangen des Dodekapropheton: Hosea und Amos", Hosea und Amos. Studien zu den Anfängen des Dodekapropheton (FAT 13; Tübingen 1996) 34-54; M.S. Odell, "The Prophets and the End of Hosea", in J.W. Watts - P.R. House (ed.), Forming Prophetic Literature, 158179; L.J. Braaten, "God Sows the Land: Hosea's Place in the Book of the Twelve", in SBLSP 2000, 218-242; J.D.W. Watts, "Hosea 1-3 and Malachi: The Outerframe of the Love of God", apresentado no Congresso Anual da Society of Biblical Literature, 2/11/1997; K.M. Craig, Jr., “Interrogatives in Haggai - Zechariah: A Literary Thread?", in J.W. Watts - P.R. House (ed.), Forming Prophetic Literature, 224-244; S.S. Tuell, "Haggai-Zechariah: Prophecy After the Manner of Ezekiel", in SBLSP 39, 263-286; P.R. House, "Dramatic Coherence in Nahum, Habakkuk, and Zephaniah", in J.W. Watts - P.R. House (ed.), Forming Prophetic Literature, 195-208.

12 Cf. J. Jeremias, "Tau und Löwe (Mi 5,6f)", in F. Crüsemann et al. (ed.), Was ist der Mensch... (FS H.W. Wolff; München 1992) 221-227; B.M. Zapff, Redaktionsgeschichtliche Studien zum Michabuch im Kontext des Dedokapropheton (BZAW 256; Berlin 1997); M.E. Biddle, "'Israel' and 'Jacob' in the Book Micah: Micah in the Context of the Twelve", in SBLSP 37/2, 850-871; E. Ben Zvi, "A Deuteronomistic Redaction in/among 'The Twelve'? A Contribution from the Standpoint of the Books of Micah, Zephaniah and Obadiah", in SBLSP 36 (Atlanta 1997) 433-459; J. Jeremias, "Die Rezeptionsprozesse in der prophetischen Überlieferung - am Beispiel der Visionsberichte des Amos", in R.G. Kratz - T. Krüger (ed.), Rezeption und Auslegung... (OBO 153; Freiburg 1997) 29-44; A. Schart, Die Entstehung des Zwölfprophetenbuchs: Neubearbeitungen von Amos im Rahmen schriftenübergreifender Redaktionsprozesse (BZAW 260; Berlin - New York 1998); M.A. Sweeney, "The Place and Function of Joel in the Book of the Twelve", SBLSP 38 (Atlanta 1999) 570-595; A. Meinhold, "Zur Rolle des Tag-JHWHs-Gedichts Joel 2,1-11 im XII-Propheten-Buch", in A. Graupner - H. Delkurt - A.B. Alexander (ed.), Verbindungslinien. Festschrift für Werner H. Schmidt zum 65. Geburtstag (Neukirchen-Vluyn 2000) 207-224.

13 Cf. P.R. House, The Unity of the Book of the Twelve (Sheffield 1990).

14 Cf. J. Nogalski, Literary Precursors to the Book of the Twelve (Berlin - New York 1993); Id., Redactional Processes in the Book of the Twelve (Berlin - New York 1993).

15 Cf. B.A. Jones, The Formation of the Book of the Twelve: A Study in Text and Canon (Atlanta 1995). 
de R. Rendtorff ${ }^{16}$ e P. Reddit ${ }^{17}$. Finalmente, em 1998, marcou seu lugar o estudo de A. Schart ${ }^{18}$. As principais contribuições destes autores serão vistas abaixo, em 1.2.

Estudos sobre a profecia em geral, com especial referência à formação do Livro dos Doze, surgem a partir de 1993. Destacam-se os trabalhos de Collins e Steck. Collins ${ }^{19}$ desenvolve a tese de que cada um dos grandes complexos que compõem a literatura profética (Is, Jr, Ez e os Doze) apresenta uma unidade interna. Dá como exemplo os Doze, que mostrar-se-iam coesos enquanto começam e terminam com os mesmos temas. Steck ${ }^{20}$ analisa o processo de crescimento da tradição profética até o texto final. O desenvolvimento dos livros proféticos ter-se-ia dado não por simples adições, mas por "releituras". Como exemplos utiliza sobretudo Isaías e os Doze.

Atualmente o tema continua a ser estudado sistematicamente em alguns congressos promovidos pela Society of Biblical Literature (USA). Publicações conjuntas sobre o tema, a cargo de autores especialmente dedicados a esta problemática, têm também vindo à luz e comprovam o desenvolvimento da pesquisa ${ }^{21}$.

\subsection{Argumentação para a unidade dos Doze}

O estudo os doze profetas como unidade parte da observação de dados da tradição. Assim, o texto de Sir 49,10 indicaria, ao lado do livro de Isaías (Sir 48,22), Jeremias (Sir 49,6-7) e Ezequiel (Sir 49,8), não cada um dos "pequenos profetas", mas os doze considerados como um único livro:

16 Cf. R. Rendtorff, "How to Read the Book of the Twelve as a Theological Unity", in SBLSP 36, 420-432.

17 Cf. P.L. Reddit, "The Production and Reading of the Book of the Twelve", in SBLSP 36, 394-419. O autor segue assim, de perto, uma das intuições mais fortes de Nogalski.

18 Cf. A. Schart, Die Entstehung des Zwölfprophetenbuchs.

19 Cf. T. Collins, The Mantle of Elijah: The Redaction of the Prophetical Books (Sheffield 1993).

20 CF. O.H. Steck, Die Prophetenbücher und ihr theologisches Zeugnis. Wege der Nachfrage und Fährten zur Antwort (Tübingen 1996).

21 Dentre as obras coletivas mais recentemente editadas, destacam-se: J.D. Nogalski - M.A. Sweeney (ed.), Reading and Hearing the Book of the Twelve (Atlanta 2000); Society of Biblical Literature. Seminar Papers 41 (Atlanta 2002); E. Zenger (ed.), "Wort JHWHs, das geschah..." (Hos 1,1). Studien zum Zwölfprophetenbuch (Herders Biblische Studien 35; Freiburg 2002); P. Reddit - A. Schart (ed.), Thematic Threads in the Book of the Twelve (BZAW 325; Berlin - New York 2003). 


\begin{abstract}
"Porque Ezequias fez o que agrada ao Senhor e se mostrou forte, seguindo seu pai Davi, como lhe ordenou o profeta Isaías, o grande, o fiel em suas visões...

Os inimigos incendiaram a cidade santa eleita, reduziram suas ruas a deserto, segundo a palavra de Jeremias. Porque eles o maltrataram, a ele, consagrado profeta desde o seio materno... Ezequiel contemplou uma visão de glória, que Deus lhe mostrou sobre o carro dos querubins...

Quanto aos doze profetas, que seus ossos refloresçam de seu sepulcro, porque eles consolaram Jacó, eles o resgataram na fé e na esperança."
\end{abstract}

Estas passagens do Sirácida referir-se-iam aos profetas considerados já dentro da ordem canônica dos escritos. A referência a Ml 3,23-24 em Sir 48,10 , por outro lado, indicaria que a coleção já estaria completa na época da redação do Ben Sirah (cerca de 200 a.C). O fato de se falar dos doze no contexto do louvor aos antigos (Sir 44 - 50) seria interessante quanto à relação entre os doze e o cânon bíblico. Os doze entrariam no esquema histórico destes capítulos e seriam colocados na época da reconstrução do Templo, com as reformas de Neemias, Ageu e Zacarias. A referência às grandes figuras de Israel mostraria que o autor conhecia a coleção de textos sagrados, que incluía a Torah, os livros proféticos e outros escritos não determinados (cf. Prólogo, 8-10) ${ }^{22}$. Dessa forma, a referência seria aos livros, não simplesmente aos personagens. Os Doze, então, seriam vistos em conjunto.

Também a tradição manuscrita apontaria nesta direção, seja por tê-los transmitido num único rolo, seja por tê-los denominado de forma complexiva.

A tradição massorética, com efeito, reuniu os doze num só rolo, distinguindo a dimensão do espaço em branco que deveria haver entre cada um dos doze profetas daquele que deveria existir entre estes e os outros profetas: entre os "pequenos" profetas, o espaço seria menor, de três linhas em branco; entre eles e os outros profetas o espaço seria de quatro linhas. Esta diferença de espaço encontra-se determinada no Tratado Baba Batra 13b do Talmud Babilônico:

"Entre um dos cinco livros da Torah e outro livro da Torah, quatro linhas, e, de modo semelhante, entre um profeta e outro profeta; mas, no que tange a um profeta dos doze, três linhas" 23 .

22 Cf. B.A. Jones, The Formation of the Book of the Twelve, 8-9.

23 Tradução a partir de E. Ben Zvi, "Twelve Prophetic Books or 'The Twelve': a Few Preliminary Considerations", in J.W. Watts - P.R. House (ed.), Forming Prophetic Literature, 102 
Por outro lado, a massora final encontra-se não somente após cada um dos livros individuais, mas também no final do conjunto, onde se indica, além do número de versículos de Malaquias, o total desde Oséias. Além disso, a ordem dos livros seguida nos manuscritos hebraicos é fixa: Os, Jl, $\mathrm{Am}, \mathrm{Ab}, \mathrm{Jn}, \mathrm{Mq}, \mathrm{Na}, \mathrm{Hab}, \mathrm{Sf}, \mathrm{Ag}, \mathrm{Zc}$ e Ml. Isto está a indicar uma uniformidade característica do respeito religioso pelo escrito. Os fragmentos descobertos em Wadi Murabba'at (séc. II a.C.) apresentam um texto consonântico praticamente idêntico ao que será utilizado na tradição massorética e confirma, desse modo, a fixação da ordem dos escritos e a tradição textual ${ }^{24}$.

Também a tradução grega da Septuaginta parece confirmar a transmissão do livro como uma unidade ao denominá-los como um conjunto: os dodekaprophéton. A ordem dos seis primeiros livros difere da encontrada nos manuscritos hebraicos, pela colocação de Jl após Miquéias, transposto por sua vez para depois de Amós. A ordem é, então: Os, Am, Mq, Jl, Ab, Jn, Na, $\mathrm{Hab}, \mathrm{Sf}, \mathrm{Ag}, \mathrm{Zc}$ e Ml. Também o manuscrito $8 \mathrm{Hev}$ XII gr, descoberto em Nahal Hever em 1952 (do final do primeiro século a.C.), com fragmentos de Jn, Mq, Na, Hab, Sf e Zc, atesta a unidade do livro e confirma a ordem hebraica dos escritos ${ }^{25}$.

O fragmento $4 \mathrm{QXII}{ }^{\mathrm{a}}$, da metade do século II a.C., com partes de Zc, $\mathrm{Ml}$ e Jn, o mais antigo dos sete manuscritos concernentes aos doze encontrados em Qumran, atesta igualmente a transmissão dos doze num só livro. A ordem dos escritos, no entanto, difere tanto da tradição massorética quanto da Septuaginta, uma vez que Jonas é colocado após Malaquias, com a separação de dois ou três espaços em branco. Segundo B.A. Jones, estas diferenças de ordem nas tradições manuscritas seriam indícios de diversas edições do livro dos doze e poderiam ajudar a reconstruir a história da formação do conjunto. Se é certo que há pesher sobre alguns dos livros dos doze, no entanto, a interpretação dos mesmos não seria feita considerando-se somente o próprio escrito, mas o conjunto dos doze escritos ${ }^{26}$.

-124. "Baba Batra" (= "última porta") é um dos dez tratados da quarta seção da Mishnah (que diz respeito aos Neziqin, danos); nele se trata também da elaboração de documentos e sua garantia (cf. G. Stemberger, Introduzione al Talmud e al Midrash, Roma 1995, 162).

24 Cf. P. Benoit - J.T. Milik - R. de Vaux, Les Grottes de Murabba'at (Oxford 1961). O fragmento contém textos a partir de Jl 2,20, com partes de Am, Ab, Jn, Mq, Na, Hab, Sf, Ag e Zc.

25 Sobre o assunto, cf. D. Barthélemy, "Redécouverte d'un chaînon manquant de l'histoire de la Septante", RB 60 (1953) 18-29, E. Tov, The Greek Minor Prophets Scroll from Nahal Hever (8Hev XII gr) (Oxford 1990).

26 Cf. B.A. Jones, The Formation of the Book of the Twelve, 7-9. 
Também o Novo Testamento falaria em favor da consideração dos doze como um conjunto unitário, uma vez que, em At 7,42-43, Am 5,25-27 é citado não somente como "palavra de Deus" (cf. Mt 2,11; 21,4; At 2,17; Hb 12,26) ou "escritura" (cf. Mt 26,31; Lc 7,27; 21,22; Jo 12,15 etc) ou ainda por seu nome (cf. Mt 9,25-26; At 2,17), mas como "livro dos profetas". Em At 15,15, Am 9,11-12 aparece referido como "palavras dos profetas" e At 13,40-41 cita Hab 1,5 como "o que os profetas dizem". À luz de At 7,42-43, o plural (profetas) deveria ser entendido como referido ao conjunto do livro dos doze, de maneira que na época do Novo Testamento os Doze seriam considerados uma unidade ${ }^{27}$.

Igualmente testemunhos extra-bíblicos pareceriam confirmar a unidade dos Doze. Alguns textos apócrifos citam os doze profetas numa ordem que se identifica ora com a tradição massorética (cf. 4Esd 1,39-40), ora com a tradição grega dos Setenta (cf. A vida dos profetas, c. 5-16), ora numa ordem diversa das duas anteriores (cf. Martírio e Ascensão de Isaías 4,22). Estes textos, contudo, parecem referir-se aos profetas como personagens históricos e não propriamente aos livros ${ }^{28}$.

Da mesma forma, Flávio Josefo pareceria supor a unidade dos doze ao indicar uma lista de livros sagrados contendo somente 22 livros, o que implicaria necessariamente serem os doze contados como um só escrito ${ }^{29}$. Igualmente Orígenes refere-se a 22 livros do Antigo Testamento e Melitão de Sardes fala de "os doze num livro"

A Vulgata introduz a nomenclatura "profetas menores", atestando considerar os escritos independentemente, mas, na introdução à sua tradução latina, Jerônimo fala de "unum librum esse duodecim prophetarum"31.

A partir dos dados da tradição, numerosos estudiosos pesquisaram o texto dos doze em busca de indícios que comprovassem sua unidade. Tais estudos trabalham em perspectiva tanto sincrônica como diacrônica. Os estudos sincrônicos partem em geral de considerações que se baseiam na abordagem canônica e preocupam-se com temas e leitura de conjunto ${ }^{32}$. Os traba-

27 Cf. B.A. Jones, The Formation of the Book of the Twelve, 10.

28 Cf. B.A. Jones, The Formation of the Book of the Twelve, 11.

29 Cf. Contra Apionem I, 8; cf. B.A. Jones, The Formation of the Book of the Twelve, 12; D. Scaiola, "Il libro dei dodici profeti minori nell'esegesi contemporanea. Status quaestionis", Rivista Biblica 48 (2000) 320.

30 Citados por Eusébio, Hist.Ecc. IV, 25-26; cf. B.A. Jones, The Formation of the Book of the Twelve, loc. cit.; D. Saciola, "Il libro dei dodici", 1.cit.

31 Cf. Bíblia Sacra Latina Veteris Testamenti Hieronymo Interprete (Leipzig 1873) 899.

32 Sob esta perspectiva, por exemplo, o estudo de Clements, citado na nota 5; P.R. House, citado na nota 13; e R. Coggins, “The Minor Prophets: One Book or Twelve?”, in S.E. Porter 
lhos de corte diacrônico procuram explicar a redação e formação do conjunto a partir de dois modelos: - como composição redacional, a unidade teria sido gerada pelo trabalho de diversos editores que, através de inserções, teriam criado estruturas, formulado temas comuns e estabelecido relações verbais entre os livros; - como compilação editorial, os livros teriam sido colocados num só conjunto pelo editor final, que teria percebido as relações já existentes entre eles ${ }^{33}$.

Os diversos elementos evidenciados pelos autores como indicadores da unidade podem ser agrupados em indícios temáticos e indícios formais. Alguns estudiosos procuram, como forma de trabalho alternativa, apresentar argumentos textuais.

\section{a) Os indícios temáticos}

P.R. House procura demonstrar a unidade dos Doze partindo de dois elementos: a abordagem aristotélica da crítica dos gêneros, a partir da qual considera a profecia como um gênero próprio; e o estudo do plano literário (estrutura, enredo, personagens) e dos temas. House propõe uma mudança global de perspectiva no estudo, na base da hipótese da unidade dos pequenos profetas. Tanto a crítica das fontes como a crítica das formas e a análise retórica, assim como a crítica da tradição, não teriam considerado ou teriam deixado em plano absolutamente secundário o livro em sua totalidade, de forma que seus resultados seriam necessariamente parciais ${ }^{34}$. House aceita as contribuições destas análises, mas as integra dentro de uma metodologia orientada pela abordagem canônica tal qual formulada por R. Clements (que valoriza a mensagem do texto final e não sua pré-história), juntamente com a crítica literária (no sentido de estudo da forma final do texto), que considera as relações verbais e o gênero literário ${ }^{35}$.

O principal fator que comprovaria a unidade dos doze seria, para House, a coerência de mensagem entre estes escritos, se considerados em seus traços essenciais. Construído sobre a base de uma seqüência bem determinada, de uma estrutura e plano geral com características próprias, o conjunto apresentaria uma mensagem unificada em torno dos temas pecado - punição - restauração ${ }^{36}$. O tema do pecado caracterizaria os seis primeiros escritos (de Os a Mq); o da punição, os três seguintes (Na, Hab e Sf) e o da restauração, os três últimos (Ag, Zc e Ml). O estudo do tema da restauração nos Do-

- P. Joice - D.E. Orton (ed.), Crossing the Boundaries. Essays in Honour of M.D. Goulder (Leiden - New York - Köln 1994).

33 Cf. D. Scaiola, "Il libro dei dodici", 321. Ainda: E. Zenger, "Das Zwölfprophetenbuch", in

E. Zenger (ed.), Einleitung in das Alte Testament (Stuttgart 2004 ${ }^{5}$ ) 517-519.

34 Cf. P. House, The Unity of the Twelve, 22-25.

35 Cf. P. House, The Unity of the Twelve, 26.

36 Cf. P. House, The Unity of the Twelve, 71-73. 
ze demonstraria que as idéias de retornar ao Senhor, procurá-lo, temê-lo, bem como a concepção do "dia do Senhor" e da renovação do povo estão interligados no conjunto e, conferindo-lhe uma grande unidade, indicariam pontos fundamentais da sua teologia ${ }^{37}$.

Também para R. Coggins ${ }^{38}$ é a estrutura global dos doze que configura o ponto central de sua unidade. Tal esquema, porém, diferentemente de House, é identificado em: palavras de juízo (Os, Am, M1); oráculos contra as nações estrangeiras ( $\mathrm{Na}, \mathrm{Hab}, \mathrm{Sf}$ 1-2); e palavras de esperança (Ag, Zc, Ml). Além disso, haveria temas que perpassariam o todo. Coggins dá dois exemplos: a relação de Israel com os povos estrangeiros e a atitude em relação ao culto. Quanto ao primeiro, pareceria haver, nos textos, uma tendência a generalizar o poder hostil, ultrapassando o dado histórico e apresentando-o como força oposta a Israel, sem uma identificação concreta. Os Doze, sob este ponto de vista, apresentariam um desenvolvimento harmonioso: na primeira parte da coleção, tratar-se-ia de poderes que se colocam como instrumentos da punição de Deus; em Na-Hab, são adversários de YHWH e de Israel; em Ag-Zc-Ml, já não hostilizam Israel, de modo que o povo eleito pode viver tranqüilo ao lado dos estrangeiros. Quanto ao tema do culto, primeiramente a mensagem é de sua condenação, para no final a comunidade passar a celebrar um culto purificado (cf. Ag, Zc, Ml).

Igualmente T. Collins, embora considerando também a repetição de expressões, focaliza como ponto central da unidade os temas, sobretudo os que ocorrem no início e no fim de seções dos diferentes livros. Os principais temas recorrentes são: aliança e eleição; fidelidade - infidelidade; afastamento - retorno; a justiça e a misericórdia de Deus; o reinado de Deus; o lugar da morada de Deus (no templo, em Sião); as nações estrangeiras como inimigas ou aliadas ${ }^{39}$. Além disso, aponta uma moldura global, constituída pela correspondência entre a metáfora pai-filho empregada no início da coleção em Oséias (cf. Os 11,1-2) e no final do conjunto, em Ml 1,6-7 ${ }^{40}$.

Já para P.L. Reddit, é o emprego de temas de transição uma das técnicas redacionais utilizadas para criar a unidade. Assim, por exemplo, Miquéias termina acenando para a destruição da Assíria e Habacuc anuncia a vinda

37 Tal tese é desenvolvida no artigo "Endings as New Beginnings. Returning to the Lord, the Day of the Lord, and Renewal in the Book of the Twelve", in SBL.SP 41 (Atlanta 2002) 258284.

38 Cf. R. Coggins, “The Minor Prophets: One Book or Twelve?”, 57-68.

39 Cf. T. Collins, The Mantle of Elijah, 65.

40 Cf. T. Collins, The Mantle of Elijah, 81. Cf. também J.D.W. Watts, "A Frame for the Book of the Twelve. Hosea $1-3$ and Malachi", in J.D. Nogalski - M.A. Sweeney, Reading and Hearing the Book of the Twelve, 209-217. 
de Babilônia ${ }^{41}$. Por outro lado, R. Rendtorff aponta, para além de numerosas correlações de temas e vocabulário, uma unidade indicada por temáticas unificadoras, das quais a principal seria a do Yôm YHWH (Dia de YHWH). Embora desenvolvida de modo heterogêneo nos livros individuais, o conjunto apresentaria ao leitor um todo coerente, que o levaria a refletir sobre as diversas concepções acerca deste $\mathrm{Dia}^{42}$.

b) Os indícios formais

Destacam-se, quanto ao estudo dos indícios formais, as obras de J. Nogalski. Sua metodologia é de corte redacional e se concentra no estudo dos elementos de intertextualidade, isto é, de relações intencionais entre os escritos devidas ao trabalho de redação ou edição. Nogalski aponta, para além da intertextualidade a nível de temas e motivos, quatro tipos de intertextualidade de índole formal ${ }^{43}$ :

- Citação: repetição textual de uma frase ou parágrafo existente em outra fonte.

- Alusão: ligação com outros textos evocada por termos comuns.

- Palavras gancho: utilização de termos significativos para ligação imediata de textos, geralmente (embora não exclusivamente) textos seguidos, no final de um livro e no início de outro, e que servem para dirigir a leitura.

- Elementos emolduradores: elementos literários colocados em posição de moldura (títulos, gêneros literários, estruturas paralelas, palavras gancho, alusões).

Os dados de maior importância, para Nogalski, são fornecidos pelas palavras gancho. Tal fenômeno, para o autor, não poderia ser considerado acidental, podendo ser interpretado seja como inserção intencional finalizada a criar relação entre escritos que existiam independentemente, seja como elementos já pré-existentes que conduziram, por este mesmo fato, à reunião dos escritos e sua colocação em determinada seqüência. Para Nogalski, não há uma solução universal; cada caso deve ser analisado particularmente. Seu estudo visa principalmente verificar se estas palavras se devem à redação ou se lhe seriam pré-existentes; ou ainda se poderiam ser, em algumas passagens, casuais ${ }^{44}$. Sua conclusão é a de que os escritos não foram reunidos

41 Cf. P.L. Reddit, "The Production and Reading of the Book of the Twelve", 398.

42 Cf. R. Rendtorff, "Alas for the Day! 'The Day of the Lord' in the Book of the Twelve", T. Linafelt - T.K. Beal (ed.), God in the Fray: A Tribute to Walter Brueggemann (Minneapolis 1998) 186-197.

43 Cf. J. Nogalski, "Intertextuality and the Twelve", in J.W. Watts - P.R. House (ed.), Forming Prophetic Literature, $102-124$.

44 Numa série de artigos, J. Nogalski procurará demonstrar sua tese através da análise de diversos textos. Assim, à guisa de exemplo: "The Redactional Shaping of Nahum 1 for the 
porque possuíssem termos comuns, mas a relação entre eles foi propositalmente criada ${ }^{45}$.

Alguns dos indícios apontados por Nogalski foram posteriormente desenvolvidos também por outros autores, como a utilização de frases recorrentes. Por exemplo, a referências às "profundezas do mar" (só em Jn 2,4 e Mq 7,19 na Bíblia Hebraica), o uso de Ex 34,6-7 em J1 2,12-14.18; Jn 3,9; 4,2; Mq 7,18-19; Na 1,3 $3^{46}$. Ou a repetição de Am 1,2 em J1 4,16 ${ }^{47}$. Textos em posição de moldura que se relacionariam a partir do trabalho de edição da coleção seriam: Os 14,5-9 e Jl 1,2; 4,16; Am 1,2; Am 9,11-12 e Ab (ênfase em Edom); Mq 7,18-20 e Na 1,2-8; Na 3,15-17 e Hab 3,17 (com alusões a J1 $1,4 ; 2,25)$; Sf 3,18-20 e Ag 1 (naquele tempo - o tempo chegou); Zc 8,9-23 e Ml 1,1-14.

Schart parte do princípio de que, se há uma unidade entre os doze, deveria haver uma estrutura global. Diante da dificuldade de se discernir entre relações intencionais e acidentais, Schart dá atenção particular aos títulos como elementos emolduradores mais seguros que vêm certamente do editor $^{49}$. Este elemento formal, que introduz uma perspectiva temporal na coleção, além de fundamentar a unidade, permitiria identificar o processo de formação da coleção ${ }^{50}$.

A consideração dos títulos é também o melhor ponto de partida para $\mathrm{R}$. Albertz $^{51}$. Os quatro escritos datados (Os, Am, Mq, Sf), com exceção de Oséias (que foi colocado antes de Amós por questões teológicas), apresentam uma ordem cronológica. Partindo da tese de Nogalski e de Schart e ana-

\footnotetext{
Book of the Twelve", in P.R. Davies - D.J.A. Clines (ed.), Among the Prophets (Sheffield 1993) 193-202; "The Day(s) of YHWH in the Book of the Twelve", in SBLSP 38, 617-642.

45 Cf. J. Nogalski, Literary Precursors, 215.

46 Assim P.L. Reddit, "The Production and Reading of the Book of the Twelve", 398.

47 Cf. R. Coggins, “The Minor Prophets: One Book or Twelve?", 64.

48 Cf. Reddit, "The Production and Reading of the Book of the Twelve", 397.

49 Cf. A. Schart, "Redactional Models: Comparisons, Contrasts, Agreements, Disagreements", SBLSP 37/2, 902. Igual valor aos títulos é dado também, dentre outros, por R. Rendtorff, "How to Read the Book of the Twelve as a Theological Unity", SBLSP 36, 420-432. Sobre o valor dos títulos como elementos para se datar o ministério do profeta e a formação das coleções, cf. também D.N. Freedman, "Headings in the Books of the Eighth-Century Prophets", in J.R. Heddleston (ed.), Divine Commitment and Human Obligation. Selected Writings of David Noel Freedman. Volume One: History and Religion (Grand Rapids 1997) 367-382.

50 A tese de Schart é proposta às páginas 903-905 do citado artigo. No livro Die Entstehung des Zwölfprophetenbuchs, partindo de uma detalhada análise redacional de Amós, chega a formular uma teoria geral sobre a redação da coleção, identificando suas etapas. Síntese da pesquisa é apresentada às páginas 304-306.

51 "Exile as Purification: Reconstructing the Book of the Four (Hosea, Amos, Micah, Zephaniah), in SBL.SP 41 (Atlanta 2002) 213-233.
} 
lisando textos de cada um destes escritos, defende a existência de um "livro dos quatro", que apresentaria uma redação e teologia comuns, centrada na idéia de juízo como purificação.

c) Os indicios de indole textual

Seguindo uma distinta perspectiva, a partir dos estudos de E. Tov, B.A. Jones procurou demonstrar que elementos de crítica textual podem ser indicadores de uma atividade literária-editorial. Jones leva em consideração não somente a ordem dos livros no cânon hebraico, mas ainda a da LXX e de um manuscrito encontrado em Qumran (4QXII $\left.{ }^{\mathrm{a}}\right)$. Comparando-as, conclui que suas diferenças devem ser atribuídas não a questões de ordem críticotextual, mas à atividade redacional dentro do processo de colocação no cânon $^{52}$.

Também Fuller usa a tradição manuscrita como recurso para desvendar o processo de formação dos XII. Haveria uma inter-relação entre a história e a transmissão do texto de cada um dos Profetas Menores e a história da redação dos $\mathrm{XII}^{53}$. Para Fuller, 4QXIIa\&b testemunharia que na metade do século II a.C. a coleção em hebraico já estava completa. Isto é confirmado pela citação de Sir 49,10 (ca. 190). Os manuscritos de Qumran indicariam que a coleção era composta por todos os doze que hoje conhecemos. A ordem dos livros, fora a exceção de 4QXIIa, parece ser a mesma conservada no texto massorético e falaria em favor da antigüidade (início do $1^{\circ}$. século a.C.) da ordem que será a da tradição massorética. Isto seria confirmado pelo manuscrito grego de $8 \mathrm{HevXIIgr}(100$ - 50 a.C.). Ou seja: a ordem da tradição massorética data ao menos do final do século II ou início do século I. Quanto à ordem dos livros da LXX, a primeira evidência parece ser encontrada no Papiro de Washington.

\section{Discussão da tese}

Os argumentos apresentados pelos autores e que merecem ser avaliados podem ser agrupados em duas categorias: - a tradição manuscrita, as diferentes tradições textuais e o testemunho da tradição judaica; - a questão da intertextualidade, referida às citações, alusões e semelhanças temáticas e ao recurso a palavras gancho. Na discussão destes elementos, E. Ben Zvi

52 Cf. B.A. Jones, The Formation of the Book of the Twelve: A Study in Text and Canon (Atlanta 1995).

53 R. Fuller: "The Form and Formation of the Book of the Twelve: The Evidence from de Judean Desert", in J.W. Watts - P.R. House (ed.), Forming Prophetic Literature, 86-101; "The Text of the Twelve Minor Prophets", CR:BS 7 (1999) 81-95. O.H. Steck (cf. "Zur Abfolge Maleachi - Jona in 4Q76 [4QXIIa] ZAW 108, 1996, 248-253) esclarece dados do estudo de Fuller com a apresentação de 4QXIIa. 
desenvolveu uma série de perspicazes observações, que nos servem como ponto de partida para a reflexão ${ }^{54}$.

\subsection{Os dados da tradição}

Não se pode dizer que os dados da tradição manuscrita (a colocação dos Doze num único rolo, a massora final e o título complexivo dado pela LXX) sejam inequívocos e garantam, por si só, a unidade dos escritos. Com efeito, o fato de se encontrarem sob um único título não significa necessariamente terem sido editados com a intenção de formarem um só livro, ao lado de Is, Jr e Ez. Mesmo no caso de que se pudesse constatar ter sido este o pensamento dos responsáveis pela tradição manuscrita, tal fato não teria relevância para a questão, pois aportaria a compreensão dos transmissores do texto e de grupos de tempos posteriores (a evidência mais remota, de 4 QXII ${ }^{\mathrm{a}}$, é da metade do século II), mas não, necessariamente, o pensamento dos editores. Igualmente, caso se considere que Sir 49,10 se refira a um único rolo, a data desta menção é certamente muito posterior à da composição dos livros, de modo que traria a compreensão de um grupo tardio e não necessariamente a dos editores.

Ou seja, ainda que se pudesse garantir que os doze ou seus precursores foram transmitidos em um único rolo já na época persa ou mesmo antes, isto não significaria que eles tivessem sido pensados como uma unidade e fossem mais do que uma coletânea de escritos independentes, juntados uns aos outros. Assim se expressa Ben Zvi: "one scroll does not necessarily mean one single, literary unity that was (or must have been) (re)read as such" ${ }^{\text {} 5}$. Por outro lado, há nos textos de Qumran evidências de que um rolo não significa necessariamente uma unidade literária. Há textos próprios da comunidade de Qumran que foram encontrados num único rolo, mas que, no entanto, são claramente independentes entre $\mathrm{si}^{56}$. Além disso, os Doze, mesmo escritos num só rolo em Qumran, são no entanto comentados separadamente, em diferentes pesharim, que consideram individualmente os escritos a que se referem e não os comentam em referência ao todo que comporiam. Igualmente, nada faz crer que os textos rabínicos ou a tradição massorética, que

54 Cf. E. Ben Zvi, “Twelve Prophetic Books or 'The Twelve': a Few Preliminary Considerations", in J.W. Watts - P.R. House (ed.), Forming Prophetic Literature, 125-156.

55 E. Ben Zvi, "Twelve Prophetic Books or "The Twelve", 131: "um rolo não significa necessariamente uma unidade literária individual que foi (ou deve ter sido) (re)lida como tal".

56 Cf. E. Ben Zvi, "Twelve Prophetic Books or 'The Twelve”, 132, n. 23. 
conheceram o rolo único, interpretassem o livro como um todo, vendo nele mais do que uma coleção de diversos escritos ${ }^{57}$.

Quanto à questão do Tratado Baba Batra 13b, acentua Ben Zvi não se poder afirmar com segurança que ateste a unidade literária dos doze. Ao contrário, a leitura atenta e desarmada do texto leva a crer que cada livro é visto como um livro e não como um capítulo dentro de uma obra única. Pois cada escrito singular dos doze é chamado de "profeta" tanto quanto os outros livros proféticos: "entre um profeta e outro profeta; mas, no que tange a um profeta dos doze..." (grifos nossos). Em outras palavras, é na sua singularidade, e não em seu conjunto, equiparado aos outros livros proféticos. A distinção de dimensão do espaço linear entre os profetas dos doze e os outros, bem como o fato de a massora final trazer, além do número de versículos de Malaquias, também o total de Oséias e Malaquias, não se constitui em dado suficiente para se postular a unidade literária dos doze. Pois a massora no final de cada um dos pequenos escritos é também forte indício de que cada escrito é considerado como uma unidade independente. A massora ao final dos doze corresponderia, nesse caso, à intenção de manutenção da integridade do texto contido no rolo inteiro, não acarretando, portanto, maiores conseqüências para a consideração de cada um dos escritos, que, aliás, como será desenvolvido mais abaixo, mantêm todos um título próprio. Também o espaço levemente diminuído entre os pequenos profetas não exige ser interpretado como indício de unidade dos mesmos. Estes elementos poderiam indicar no máximo, segundo Ben Zvi, serem os doze compreendidos como um conjunto, uma coleção, sem que com isto se deva postular sua unidade literária $^{58}$.

Por outro lado, o próprio Baba Batra (n. 14b) menciona que a organização lógica dos profetas levaria a colocar Oséias antes de Isaías. Esta observação tem interesse na medida em que mostra que, para este Tratado, Oséias (pelo menos) era considerado um escrito à parte. Também o texto de Números Rabbah 18.17 separa o livro de Jonas dos outros onze, talvez na intenção de formular um pentateuco profético (Is, Jr, Ez, Onze, Jn) ${ }^{59}$, o que testemunha em favor de sua independência e corrobora o que foi dito acima.

Outro fator digno de atenção é a diferença de ordem dos escritos nas tradições textuais. Esta diversidade põe seriamente à prova a tese de que haveria uma leitura, aceita por uma comunidade, que incluiria a compreen-

57 Cf. E. Ben Zvi, "Twelve Prophetic Books or 'The Twelve"”, 131-132.

58 Cf. E. Ben Zvi, "Twelve Prophetic Books or 'The Twelve", 1.cit.

59 Cf. E. Ben Zvi, "Twelve Prophetic Books or 'The Twelve'”, 132, n. 22. Números Rabbah é um midrash de tipo homilético que comenta o livro dos Números (cf. G. Stemberger, Introduzione al Talmud e al Midrash, 432-434). 
são dos doze em sua totalidade. Pois se a ordem dos escritos varia, então também a conexão entre eles e, portanto, o desenvolvimento das idéias. A mudança de ordem implica diretamente a mudança de leitura, o que contraria a tese de um plano unitário que conduziria de livro a livro.

\subsection{A questão da intertextualidade}

No que concerne aos indícios intertextuais, parece não se dever supervalorizar a presença de textos paralelos, citações, alusões ou semelhanças temáticas. Pois textos aparentados e semelhanças temáticas encontram-se não só no interior dos doze, mas também entre estes e outras obras proféticas (ou mesmo outras partes da Bíblia Hebraica). Não se poderia dizer que, com estas semelhanças, Is, Jr, Ez e os doze pequenos profetas formariam um só livro. Poder-se-ia dizer no máximo que eles formam uma coleção de livros proféticos (no plural) com pontos em comum. Somente se os elementos de intertextualidade entre os doze fossem tão fortes e característicos que os distinguissem claramente dos outros três então se poderia pensar deverem eles ser considerados uma obra a se. Mas tal não parece ser o caso.

A presença de elementos comuns entre os livros (e não só entre os doze) pode ser em parte - para além da análise redacional - explicada pela existência de elementos fixos, teológicos e literários, que teriam influenciado a redação de textos originados em circunstâncias semelhantes. Pelo que se pode observar na Bíblia Hebraica, poder-se-ia também supor, segundo Ben $\mathrm{Zvi}^{60}$, que estes repertórios de elementos fixos não fossem muito vastos, mas limitar-se-iam ao mais importante, numa dimensão tal que permitisse sua fácil utilização.

Outra possibilidade de explicação baseia-se na tese de que todo texto apresenta uma abertura de significado, de modo que a relação entre textos é concebida como reinterpretações em novas circunstâncias e não necessariamente expedientes com objetivo de ligar escritos diversos ${ }^{61}$. É assim que, à guisa de exemplo, os textos de Habacuc, em estudo recente, são relacionados com o livro do Deuteronômio e de Samuel (Hab 3,3 e Dt 33,2; Hab 3,19 e Dt 33,29; Hab 3,19bc e 2Sm 22,34) ${ }^{62}$.

60 Cf. E. Ben Zvi, "Twelve Prophetic Books or 'The Twelve", 136-137.

61 Também esta explicação situa-se na categoria de "intertextualidade", aqui, porém, entendida de modo muito mais amplo do que foi explanado pelos autores acima citados. Sobre esta categoria, cf. R.L. Schultz, The Search for Quotation. Verbal Parallels in the Prophets (JSOT.S 180; Sheffield 1999); S. Moyise, "Intertextuality and Biblical Studies: A Review", Verbum et Ecclesia 23 (2002) 418-431.

62 Cf. D. Markl, "Hab 3 in intertextueller und kontextueller Sicht”, Bib 85 (2004) 99-108. 
Além disso, a observação das semelhanças não deveria deixar na obscuridade as diferenças. A experiência nos mostra que muitas vezes o que muito impressiona num primeiro momento pode ser facilmente desfeito num segundo passo, ao se atentar - para além dos pontos em comum - para as diferenças existentes.

Chama a atenção, neste particular, a dose de subjetivismo que pode estar presente na análise de muitos autores ${ }^{63}$. Isto se aplica de modo particular ao fenômeno das palavras-gancho. Já A. Schart, embora forte defensor da unidade dos doze, observara o problema envolvido na tese de Nogalski, ao ter este autor limitado sua análise aos capítulos iniciais e finais dos livros, deixando de lado muitos outros pontos de contato ${ }^{64}$. Mas é Ben Zvi que desenvolverá uma discussão detalhada deste fenômeno, ao testá-lo no livro de Abdias. Com toda certeza, não se pode negar o uso de palavras-gancho como meio para criar unidade numa coleção ou num livro. Devem, no entanto, ser consideradas ao lado de outros elementos e, sobretudo, dentro dos contextos em que se encontram, com sua valência semântica específica. Como exemplo disto, Ben $\mathrm{Zvi}^{65}$ considera as palavras-gancho apontadas por Nogalski no final de Abdias (v. 15-21) e início de Miquéias (Mq 1,1-7) הִ (montanha),

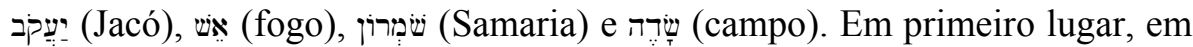
se tratando de cinco palavras muito comuns na Bíblia Hebraica, mesmo encontrando-se próximas umas das outras, torna-se problemática sua interpretação como indício suficiente de intertextualidade. Por outro lado, as palavras são consideradas isoladamente e não no seu contexto. Com isto, a signi-

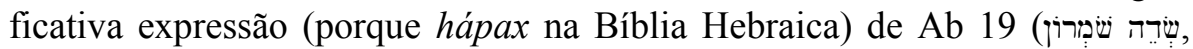
campo de Samaria) é desmembrada em seus termos, deixando de ser considerada em sua especificidade. Ben Zvi observa com agudeza que em Ab 19 ocorre também a expressão שִדה אפרברים (campo de Efraim); se fosse considerado o termo "Efraim" e não "Samaria", haveria cinco termos que conectariam Ab 15-19 com o S1 78. Se, ao contrário, se colocasse Amós após Abdias, ter-se-ia encontrado quatro palavras comuns entre Ab 20-21 e Am 1,1-9: צִין

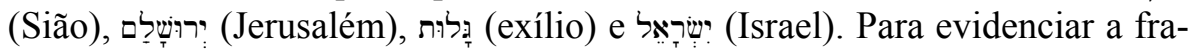

63 Também D. Scaiola sublinha este ponto: cf. "Il libro dei dodici”, 323.325. Igualmente I. Willi-Plein realça, no que concerne à reconstrução redacional, que a tese de Nogalski descreve como se poderia ter dado a formação do livro dos doze, mas deixa aberta a possibilidade de que também poderia ter sido diferente: cf. "Das Zwölfprophetenbuch", in Theologische Rundschau 64 (1999) 394.

64 Cf. a recensão de A. Schart às duas obras de Nogalski de 1993 (Literary Precursors e Redactional Processes) em Theologische Literatur Zeitung 121 (1996) 648.

65 Cf. E. Ben Zvi, "Twelve Prophetic Books or 'The Twelve"”, 139-142.

66 Cf. J. Nogalski, Literary Precursors, 31-33. A conexão é feita entre Abdias e Miquéias porque, segundo Nogalski, Jonas foi introduzido posteriormente no livro dos Doze. 
gilidade deste procedimento, nosso autor dá ainda como exemplo o final de Jeremias (Jr 52,31-34) e o início de Ezequiel (Ez 1,1-2). Caso fossem aproximados, também seriam encontrados termos comuns. No entanto, a par dos vocábulos semelhantes, haveria tantas diferenças que dificilmente se chegaria à conclusão de que estes termos estão ali conscientemente colocados para que as duas obras sejam lidas como uma só ${ }^{67}$.

Em outras palavras, é problemático o critério das palavras gancho, tanto mais se não é considerado o horizonte semântico das mesmas nos seus contextos específicos. Além disso, a preocupação acentuada com palavras gancho tira a atenção de outros elementos que também deveriam ser considerados, isto é, os aspectos próprios do texto que finaliza um livro.

A conclusão de Ben Zvi é clara:

$$
\begin{gathered}
\text { "Nogalski's observation is not a property of the text by itself but } \\
\text { results from the significance he attaches from the outset to the } \\
\text { sequence Obadiah-Micah" } " \text {. }
\end{gathered}
$$

Em suma, a importância dada ao fenômeno das palavras-gancho como criadoras da unidade dos doze parece dirigir como um a priori o pensamento e as conclusões de Nogalski. Não se pode negar o fenômeno das palavras gancho na Bíblia Hebraica e nem que há recorrência de termos entre o final de um livro e o início de seu subseqüente nos doze (dependendo da ordem que se siga). No entanto, com Ben Zvi retemos que, no que tange ao estudo dos doze, o problema que se apresenta é que estes pontos foram interpretados como elemento unificador porque já se partia da idéia de que os doze são uma única obra ${ }^{69}$. Com isto, a argumentação se caracteriza como um círculo vicioso e carece, portanto, de poder comprobatório. Não é possível avaliar a hipótese de que os doze sejam uma unidade se já de antemão se afirma que eles são uma unidade.

\subsection{Os títulos e as finalizações dos livros e sua importância}

Uma consideração de grande significado diz respeito à falta de um título único para a coleção ${ }^{70}$ (ou de uma introdução geral que indicasse uma

67 Cf. E. Ben Zvi, "Twelve Prophetic Books or 'The Twelve'”, 140-141.

68 Cf. E. Ben Zvi, "Twelve Prophetic Books or 'The Twelve”, 140-141: "A observação de Nogalski não é uma peculiaridade do texto em si mesmo, mas resulta da importância que ele atribui de início à seqüência Abdias - Miquéias".

69 Cf. E. Ben Zvi, "Twelve Prophetic Books or "The Twelve", 142.

70 Evidentemente, a denominação dodekaprophéton da Septuaginta não pode ser considerada com propriedade um título para o conjunto. 
leitura unificada dos mesmos) e à manutenção, por outro lado, dos títulos em todos os diferentes escritos, sejam eles datados ou não. Alguns autores reconhecem que os títulos guardam cada livro como um todo com características próprias, sem no entanto eliminarem a coerência do conjunto unificado a partir de temas e vocabulário ${ }^{71}$; outros, procuram reconstruir, a partir deles, a formação do conjunto ${ }^{72}$. Para Ben Zvi, no entanto, os inícios dos diversos livros são a principal indicação de que cada escrito apresenta-se como independente, portanto, no mesmo patamar dos livros de Isaías, Jeremias e Ezequiel.

O livro de Isaías oferece dados para uma justa apreciação do valor dos títulos. De fato, embora seja fruto da coleção e reelaboração de escritos de épocas e autores diferentes (ao menos os assim chamados primeiro, segundo e terceiro Isaías), suas três grandes partes não foram colocadas como livros à parte. A falta de títulos no início da segunda e da terceira parte e, por outro lado, a presença de um título único no início da obra evidencia que estas devem ser lidas no conjunto associado ao profeta Isaías ${ }^{73}$. É de domínio comum que muitos títulos são fruto de atividade redacional (possivelmente numa etapa já avançada) ${ }^{74}$; isto indica que a redação, ao menos numa de suas fases, não considerou os doze escritos (ou parte deles, em possíveis estágios prévios) como formando um só livro, mas como textos com identidade própria.

Ben Zvi chama a atenção ainda para dois fatos: a estreita conexão entre as conclusões dos livros e os capítulos anteriores do mesmo, de um lado, e a tendência de cada livro possuir uma série de termos e referências cruzadas próprias, que o distingue dos outros escritos, de modo que se pode pensar que uma linguagem própria sirva também para identificar o escrito, distinguindo-o dos demais ${ }^{75}$. Com efeito, pode-se observar com clareza a propensão de as perícopes que finalizam um escrito apresentarem aspectos peculiares que, simultaneamente, colocam-na em relação particular com o escrito que estão concluindo. Isto foi já salientado, à guisa de exemplo, em relação ao texto conclusivo de Amós $(9,11-15)^{76}$ e de Oséias $(14,2-9)^{77}$.

71 Assim, por exemplo, R. Rendtorff (cf. nota 49 acima).

72 Cf. A. Schart, cf. nota 49 acima e ainda J.D.W. Watts, "Superscriptions and Incipits in the Book of the Twelve", in J.D. Nogalski - M.A. Sweeney (ed.), Reading and Hearing the Book of the Twelve, 110-124; cf. ainda R. Albertz, "Exile as Purification: Reconstructing the Book of the Four (Hosea, Amos, Micah, Zephaniah)", in SBL.SP 41, 213-233.

73 Cf. E. Ben Zvi, "Twelve Prophetic Books or 'The Twelve"”, 137.152.

74 Cf. D.N. Freedman, "Headings in the Books of the Eighth-Century Prophets", 377-380.

75 Cf. E. Ben Zvi, "Twelve Prophetic Books or 'The Twelve", 153.

76 Assim, à guisa de exemplo, acerca de Am 9,11-15: cf. M.D. Terblanche, "Rosen und Lavendel nach Blut und Eisen: Intertextuality in the Book of Amos", OTE 10 (1997) 312-321. 
No que tange ao primeiro texto, não apenas Am 9,12 apresenta seis termos comuns com Am 5,11 e quatro com Am 4,9, mas também aspectos significativos da perícope final podem ser melhor compreendidos dentro do horizonte global do livro: assim, a menção da "tenda de Davi", expressão hápax na Bíblia Hebraica, pode ser bem compreendida pela ênfase dada, no livro, à festa das cabanas ${ }^{78}$; a ênfase em Edom corresponde à ênfase igualmente dada em 1,6.9.11.12; 2,1 (dentre todas as nações aí mencionadas, Edom é a mais freqüente); a evocação do "nome" de YHWH enquadra-se bem no destaque dado ao Nome no livro (cf. 2,$7 ; 4,13 ; 5,8.27 ; 6,10 ; 9,6$ ). Estes e outros aspectos relativizam a tese de A. Schart, segundo a qual Am 9,13b-f e 9,12a seriam um acréscimo redigido com a finalidade de conectar Amós aos Doze, através da relação imediata com Joel e Abdias, particularmente pelos contatos materiais com Jl 4,18-19; Ab 17-20 $0^{79}$, textos que, por sua vez, podem ser suficientemente explicados dentro do horizonte dos respectivos livros ${ }^{80}$.

Também a conclusão de Oséias nos oferece um exemplo claro deste fato. O texto apresenta numerosos termos e expressões, bem como concepções teológicas, que se colocam em nítida contraposição ou continuidade com o restante do livro. Assim, a utilização do verbo ("voltar") em sentido próprio ou metafórico (14,2.3.8; no restante do livro, diversas vezes); a menção do "tropeçar na falta" (Os 14,2; 5,5); a transformação do culto prestado por Israel $(14,3-4 ; 7,14 ; 8,4.6 ; 13,2)$ e da condição pecadora do povo $(14,5 ; 11,7)$; as variadas imagens vegetais $(14,6-9 ; 2,10.11 .24 ; 9,1.16$; $10,1.4)$, a menção dos habitantes da terra $(14,8 ; 4,1)$, para citar somente alguns exemplos. Demonstra-se dessa maneira como o capítulo final responde às palavras reportadas no livro inteiro, desde o seu início, e tem seu sentido a partir deste contexto. Assim sendo, tornam-se questionáveis as ligações entre o final de Oséias e Joel (grão, vinho, habitantes do país, em Os 14,8 e J1 $1,10.17 ; 1,5 ; 1,2.14 ; 2,1)$ indicadas por Nogalski ${ }^{81}$, baseadas em termos ou expressões isolados, sem consideração para com o horizonte semântico e os aspectos teológicos do contexto.

77 Para maiores detalhes, ver nosso estudo Salvação entre juízo, conversão e graça. A perspectiva escatológica de Os 14,2-9 (Roma 1998).

78 Assim, Am 2,13 (feixes) e 8,1-3 (frutos maduros do verão) evocam elementos da festa das tendas. Cf. M. Sweeney, The Twelve Prophets, I (Collegeville 2000) 193.273.

79 Cf. A. Schart, Die Entstehung des Zwölfprophetenbuchs, 97-98. Quanto à relação com Joel e Abdias, Schart acolhe a proposta de Nogalski (cf. Literary Precursors, 109-110; Redactional Processes, 64-65).

80 Assim, por exemplo, a conexão entre Jl 4,18 e 1,5.17-20: cf. E. Achtemeier, The Minor Prophets, I (Peabody $\left.1999^{2} ; 1996^{1}\right) 160$.

81 Cf. J.D. Nogalski, Literary Precursors, 69-70. 
Em suma, estes dois exemplos mostram relações tão estreitas das finalizações dos livros com o contexto literário a que se referem que possíveis elementos de ligação com o escrito imediatamente posterior (as palavras gancho!) colocam-se tão em segundo plano que resultam destituídos de maior significado.

\section{Conclusões e pistas abertas}

A partir das considerações acima, não é tão pacífico assumir a tese de que os doze profetas formem um único livro no sentido de um todo coerente cujas partes devem necessariamente ser lidas e compreendidas como parte deste conjunto. Se por um lado não se pode negar existirem relações entre eles ou entre alguns deles ${ }^{82}$, não se pode, no entanto, afirmar sem problemas serem de tal ordem que liguem os diversos escritos num todo cuja valência exige ser cada um dos pequenos profetas lido à luz do conjunto.

Alguns autores, todavia, não descartam a possibilidade de vê-los unidos, mas no sentido de formarem uma antologia, uma coleção de textos. Assim é que Petersen os considera uma "antologia temática", um repertório reunido a partir de um tema, o dia de $Y H W H^{83}$. Já Ben Zvi compreende-os como um "repertório comum de um grupo social relativamente pequeno" 84 , que explicaria as concepções e formas literárias semelhantes como dependência de um horizonte comum.

A nosso ver, para que se possa ter alguma clareza acerca da questão da unidade dos doze, deve-se em primeiro lugar distinguir entre a questão redacional de cada um dos diversos escritos e a questão dos doze como um único livro. Assim, por exemplo, se se detectasse como evidente a mão deuteronomista em diversos pequenos profetas, isto não significaria necessariamente que esta redação tenha trabalhado em vista da formação de um todo coerente. Em outras palavras, uma redação comum a vários escritos não implica necessariamente uma redação unificadora. Os elementos comuns entre os doze, mesmo se proviessem de uma mesma redação não constringem à conclusão de que o todo forme uma unidade estritamente coesa.

Em segundo lugar, pensamos dever ser revalorizado o fenômeno das releituras das tradições (também escritas) feitas em Israel-Judá pelos grupos mais versados na literatura teológica. Este elemento, aplicado por Ben Zvi ao

82 Cf. o artigo de J. Jeremias, "Die Anfänge des Dodekapropheton: Hosea und Amos", in Hosea und Amos. Studien zu den Anfängen des Dodekapropheton (Tübingen 1996) 34-54.

83 Cf. D.L. Petersen, “A Book of the Twelve?", in J.D. Nogalski - M.A. Sweeney, Reading and Hearing the Book of the Twelve, 3-10.

84 Cf. E. Ben Zvi, "Twelve Prophetic Books or 'The Twelve", 155. 
nosso tema ${ }^{85}$, foi já anteriormente trabalhado de modo perspicaz - dentre outros autores - por P. Grech ${ }^{86}$ em relação à escatologia profética. Trata-se, com efeito, de um dado incontestável no que concerne à formação da livros bíblicos ${ }^{87}$. Aplicado aos doze, significa que, em diferentes momentos históricos/culturais/teológicos, a releitura da tradição profética levou à atualização da mensagem com ênfase em determinadas temáticas (por exemplo, uma nova compreensão do tema do dia de $Y H W H$ ), possivelmente com vocabulário recorrente. Isto, porém, não implica que se estivesse relacionando os diversos escritos de modo a formar um único livro. Ou seja: pode haver temáticas que perpassam os doze profetas comparados entre si mais do que se comparados com Isaías, Jeremias e Ezequiel, sem que cada um daqueles pequenos escritos deva necessariamente ser compreendido como parte de um conjunto unificado. Como resultado deste trabalho de releitura, não é só possível mas como que necessário haver pontos de contato entre os diversos escritos. Com isto, apresenta grande interesse verificar os textos que se tocam relativamente a terminologia e temática, a fim de melhor avaliar o alcance das teses teológicas neles envolvidas e melhor compreender as situações históricas, culturais, sociais, que se colocam como pano de fundo, para assim chegar a sua mais completa interpretação. Mostra-se como importante, dessa maneira, não isolar um texto ou um livro do conjunto, primeiramente dos doze, mas também, em outro nível, da literatura profética como um todo e, por fim, dos escritos bíblicos em sua totalidade. Sem negar as evidentes ou menos evidentes diferenças, com este procedimento muitos horizontes de compreensão mais abrangentes certamente podem-se descortinar. Simultaneamente, com isto atenta-se, ao menos em parte, a um dos princípios fundamentais da interpretação bíblica expressos na Dei Verbum $\left(\mathrm{n}^{\circ}\right.$ 12; até hoje, a nosso ver, não suficientemente considerados na teoria e na prática da exegese bíblica), qual seja, o de considerar a unidade da Escritura.

Em síntese, no estado atual dos estudos, parece-nos possível afirmar que os assim chamados doze pequenos profetas podem formar uma antologia; nesse sentido, apresentam uma relação entre si. Visto que a argumentação até hoje apresentada por aqueles que defendem a tese de um Livro dos Doze não se demonstra suficientemente, até que haja maior clareza nesta questão a perspectiva mais plausível de estudo destes livros seria a de considerá-los em

85 Cf. E. Ben Zvi, "Twelve Prophetic Books or 'The Twelve”, 155-156.

86 "Reinterpretazione interprofetica ed escatologia veterotestamentaria", in Ermeneutica e Teologia Biblica (Roma s.d.) 5-39.

87 Cf. a publicação das Atas da XXXVII Semana Bíblica Italiana (Roma, 9-13 de setembro de 2002), que versou sobre esta importante temática: I. Cardellini - E. Manicardi (ed.), Torah e Kerigma: dinamiche della tradizione nella Bibbia. Atti della XXXVII Settimana Biblica Nazionale (Bologna 2004). 
sua particular relação com os outros da mesma coleção (sem, no entanto, fazer abstração de outras relações que se apresentem), sem, porém, a priori afirmar que tais e tais fenômenos são devidos à sua unidade literária. Certamente um maior conhecimento de cada pequeno profeta e sua comparação com os outros livros do complexo dos doze poderá contribuir para um maior esclarecimento desta questão. Abre-se aqui um imenso campo de estudos.

\section{Résumé}

L'article vise à analyser la question de la relation entre les soi-disant "petits prophètes", afin de délimiter la nature de la possible unité qu'ils forment. Après un bref historique de la question, on discute les principaux aphorismes de la thèse, qui soutient que les Douze ne forment qu'un seul livre. Ensuite, on cherche à définir les points de référence du thème, pour mettre en évidence des pistes pour une investigation ultérieure sur les douze prophètes.

Maria de Lourdes Corrêa Lima

Professora do Departamento de Teologia da PUC-Rio Professora do Instituto Superior de Teologia da Arquidiocese do RJ Professora do Instituto de Filosofia e Teologia do Mosteiro de São Bento

(Rio de Janeiro)

Doutora em Teologia Bíblica pela Pontificia Università Gregoriana (Roma) 